\title{
Experimental and theoretical studies of strength and stress-strain properties of the concrete under conditions of complex stress-strain states with presence of tensile stresses from the effect of a single-shot dynamic load of the general form
}

\author{
Konstantin Tsvetkov ${ }^{1, *}$ \\ ${ }^{1}$ Moscow State University of Civil Engineering, Department of Strength of Materials, Moscow, \\ Russia
}

\begin{abstract}
The publication examines the generalization of results of experimental and theoretical studies of concrete under static and singleshot dynamic loading under conditions of single-axial, two-axis, three-axis stress states with the presence of tensile stresses. Dependences for determining concrete strength, concrete stress-strain modulus, concrete ultimate strains. Research results extend the idea of concrete behaviour at various types of force action and can be used in the calculation of structures for special combination of loads, taking into account the actual concrete properties.
\end{abstract}

\section{Formulation of the problem}

In order to improve the calculations of building structures for the special combination of loads, as well as when carrying out check calculations to assess the consequence of the emergency dynamic impacts, it is necessary to have the reliable information on strength and stress-strain characteristics of structural materials, taking into account the type of stressstrain state (SSS) and loading rate.

Emergency action of the dynamic load can lead to appearance of various SSS in the construction, including different to accepted in calculations for the basic combination of loads, at that the most dangerous in terms of the concrete behaviour will be zones with the presence of tensile stresses.

A limited number of studies is devoted to the assessment of the joint influence of the stress state type and increased loading rate on properties of the concrete. Carried out studies concern mainly issues of strength under biaxial and triaxial compression, at that the data on concrete behaviour under dynamic loading under conditions of complex stress states with the presence of tensile stresses are practically absent. Experimental and theoretical studies

*Corresponding author: sopromat@mgsu.ru 
of the concrete under conditions of complex SSS with the presence of tensile stresses from the action of the single-shot dynamic load of the general type expand notions about the behaviour of concrete at various power impacts. Obtained results can be used when developing the theory of concrete dynamic strength, as well as after carrying out additional studies on a larger number of samples, when varying the loading rate can be used in calculation of structures for the special combination of loads, taking into account SSS factor and the loading rate.

With account of the above it was important to carry out experimental studies of strength and stress-strain characteristics of concrete under single-axis tension and "compressiontension" stress state at static and dynamic loading.

\section{Methodology of experimental research}

Concrete prisms of 10x10x40 mm were tested. 2 series of samples were tested. Samples of the first series (P-1) were tested at "compression-tension" stress state. Samples of P-2 series were tested at "two compressions - tension" stress state. Besides, samples of both series were tested for the single-axis tension and compression.

Strength of P-1 series concrete under single-axis compression was $R_{b}=31.5 \mathrm{MPa}$, under single-axis tension $R_{b t}=2.95 \mathrm{MPa}$. P-2 series concrete had the strength for compression $R_{b}=16 \mathrm{MPa}$, for tension $R_{b t}=1.45 \mathrm{MPa}$.

When carrying out tests the set-up was used similar to that described in [1]. The difference was in the application of the reversing principle - the conversion of compressive forces into tensile, that was achieved through the use of the special device.

Fixing of samples in the set-up was carried out with the use of studs, which were screwed into heads of samples and fixed in hinged system of set-ups. Use of the hinged system allowed centring samples along the physical axis with the trial load.

The set-up allowed realization of the dynamic loading at a constant rate of stress increase. In our experiments $\dot{\sigma}_{1} \approx 70 \mathrm{MPa} / \mathrm{s}$, the destruction time was $\tau \approx 0.05 \mathrm{~s}$. Static tests were carried out with the same set-up.

Creation of compressive stresses $\sigma_{2}$ and $\sigma_{2}=\sigma_{3}$ was fulfilled with the use of membranetype set-ups, which provide the hydrostatic method of load transmission.

Experimental studies at the stress states of "compression - tension" and "two compressions - tension" were carried out according to the scheme of complex loading. At the first stage, the static compressive load was applied to the sample to a certain level from the prism strength (in our experiments: $\sigma_{2}=0.15 R_{b}, \sigma_{2}=0.3 R_{b}, \sigma_{2}=0.45 R_{b}$ or $\sigma_{2}=0.6 R_{b}$ at "compression-tension" stress state and $\sigma_{2}=\sigma_{3}=0.3 R_{b}$ - at «two compressions - tension») stress state, which value was maintained constant at the second stage of loading. At the second stage, loading of the sample was performed with static or dynamic tensile load, acting in the direction of $\sigma_{l}$ and increasing from zero to the destructive values.

At all stages of loading, forces and longitudinal strains were synchronously recorded using strain gauges, modern electronic equipment and special software.

For each level of stress $\sigma_{2}$ was tested from two to five samples at static and dynamic loading. At that, for experiments carried out under the same conditions, close results were obtained (variation coefficient did not exceed $10 \%$ ).

\section{The main results of experiments}

Main results were obtained for samples of P-1 series.

Strength experimental results of P-1 series samples are given in Fig. 1. 
Experimental results showed that the destruction at "compression-tension 'stress state takes place as a result of tensile stress achievement of a certain limit value, at that the presence of the compressive stress $\sigma_{2}$ influences the strength value in dependence on $\sigma_{2} / R_{b}$.

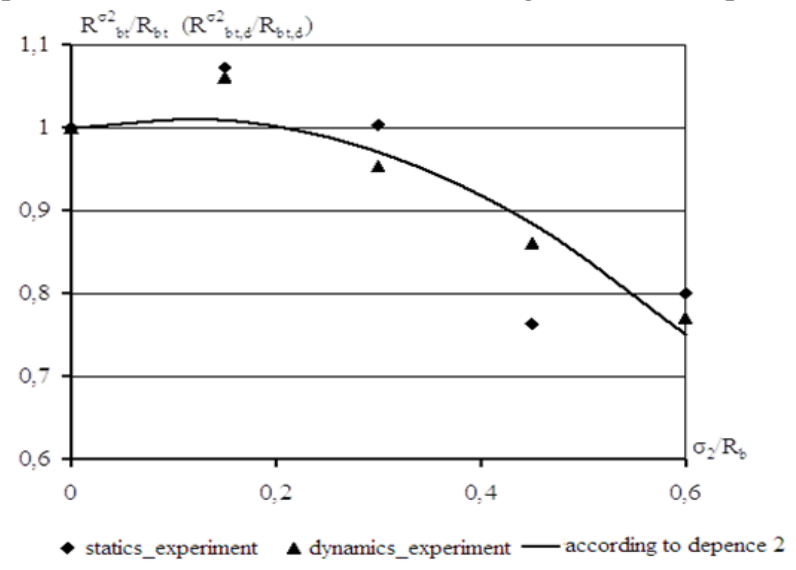

Fig. 1. The influence of the stress state type and the stress $\sigma_{2}$ at static and dynamic loading under conditions of single-axis tension and "compression - tension" stress state.

Both at statics and dynamics the following influence of $\sigma_{2} / R_{b}$ level on the concrete strength is observed. When applying compressive stresses $\sigma_{2}=0.15 R_{b}$, a certain small increase of the concrete strength (up to $7 \%$ ) takes place. At $\sigma_{2}=0.3 R_{b}$ the strength value becomes again close to the strength at the single-axis tension. Further increase of the stress level $\sigma_{2}$ keeps the tendency of the strength decrease. Obtained results as applied to the static loading coincide with the data [2].

Type of the stressed state and the level of the edging draft do not significantly influence the dynamic hardening factor, in other words, the change in the concrete strength, depending on the growth rate of stresses when "compression-tension" stress state with different levels of $\sigma_{2}$ takes place proportionally to the dynamic hardening factor corresponding to the single-axis tension.

The value of the dynamic hardening factor for the rate accepted in our studies $k_{b t, v}$ was $1.32-1.39$.

Based on the experimental studies, the attempt was made to write the concrete strength criteria under single-axis tension and "compression-tension" stress state, taking into account the type of stress state, stress level $\sigma_{2}$ and stress growth rate (1). 


$$
\left\{\begin{array}{l}
\sigma_{2} \leq R_{b t, v}^{\sigma_{2}}=k_{b t, v} F_{b t}^{\sigma_{2}} R_{b t} \\
k_{b t, v}=1.08\left(\dot{\sigma}_{1}\right)^{0.05} \\
F_{b}^{\sigma_{2}}=1+0.22\left(\frac{\sigma_{2}}{R_{b}}\right)-\left(\frac{\sigma_{2}}{R_{b}}\right)^{2} \\
0 \leq \frac{\sigma_{2}}{R_{b}} \leq 0.8 \\
10^{0} \leq \dot{\sigma}_{2} \leq 10^{2}, \mathrm{MPA} / \mathrm{s} \quad\left(10^{-4} \leq \dot{\varepsilon}_{2} \leq 10^{-2} \mathrm{url} / \mathrm{s}\right) \\
10^{-1} \leq \dot{\sigma}_{1} \leq 10^{4}, \mathrm{MPA} / \mathrm{s} \quad\left(1 \cdot 10^{-1} \leq \dot{\varepsilon}_{1} \leq 10^{-4} \mathrm{url} / \mathrm{s}\right) \\
\dot{\sigma}_{2}=\text { const }
\end{array}\right.
$$

In expression (1):

$R_{b t, v}^{\sigma_{2}}$ - concrete strength with account of the type of the stress state and loading rate;

$k_{b t, v}$ - dynamic hardening factor of the concrete at single-axis tension $(\dot{\sigma}$ - stress growth rate, $\mathrm{MPa} / \mathrm{s}$. Expression for $k_{b t, v}$ is written with the use of the data [3];

$F_{b t}^{\sigma_{2}}$ - function characterizing the influence of the stress level $\sigma_{2}$ on the change in the concrete strength under static loading. It is recorded according to the results of these studies. Factors are selected using MS Excel means;

$R_{b t^{-}}$concrete strength at the single-axis tension under static loading;

$\sigma_{1}-$ tensile stress;

$\sigma_{2}$ - compressive stress;

Limits of applicability (1) are given in accordance with the classification of loading modes, proposed in [4].

Based on measurement results of longitudinal strain values, the evaluation of the influence of stress state type, stress level $\sigma_{2}$ and the rate of loading on the concrete strain modulus and value of ultimate strains, determined with account of the first stage of loading $\varepsilon_{1, u}$ and without account of the first stage (maximum strains from action of tensile stresses) $\varepsilon_{1, u, t}$.

At static loading, the type of stress state and level $\sigma_{2}$ do not have a tangible influence on the value of concrete strain initial modulus, calculated with account of the strain curve. At the same time, with increase of the loading rate the value of the dynamic modulus decreases with the growth of $\sigma_{2} / R_{b}$.

For dynamic loading with $70 \mathrm{MPa} / \mathrm{s}$ rate there were recorded the following dependences:

for initial modulus:

$$
E_{o, d}^{\sigma 2}=E_{o, d} e^{-0.4 \sigma_{2} / R_{b}}
$$

for modulus calculated with account of the entire strain curve:

$$
E_{o, d}^{\sigma 2}=0.88 E_{o, d} e^{-0.4 \sigma_{2} / R_{b}}
$$


Factors to the power $e$ are adjusted depending on the loading rate.

In our experiments for the single-axis tension it was obtained $E_{0, d} / E_{0}=1.21$. In order to determine the dynamic initial modulus at rates which are significantly different from realized in these studies, carrying out of additional experimental studies is required.

Data on strains $\varepsilon_{l, u, t}$ and $\varepsilon_{l, u}$ are shown in Table 1.

Table 1. Ultimate strains and maximum strains from the action of the tensile load at single-axis compression and "compression-tension" stress state.

\begin{tabular}{|c|c|c|c|c|c|}
\hline \multirow{2}{*}{$\begin{array}{c}\text { Type of the } \\
\text { strain }\end{array}$} & $\mathbf{0}$ & $\mathbf{0 . 1 5}$ & $\mathbf{0 . 3}$ & $\mathbf{0 . 4 5}$ & $\mathbf{0 . 6}$ \\
\cline { 2 - 6 } & \multicolumn{5}{|c|}{ Statics } \\
\cline { 2 - 6 } & 9.3 & 12.5 & 14.0 & 14.3 & 16.8 \\
\hline $\begin{array}{c}\varepsilon_{1, \mathrm{u}}, \\
\text { url } \times 10^{5}\end{array}$ & 9.3 & 10.2 & 9.6 & 7.5 & 8.3 \\
\hline $\begin{array}{c}\varepsilon_{1, \mathrm{u}, \mathrm{t}} \\
\text { url } \times 10^{5}\end{array}$ & 10.3 & 14.0 & 14.6 & 16.6 & 18.1 \\
\hline $\begin{array}{c}\varepsilon_{1, \mathrm{u}}, \\
\text { url } \times 10^{5}\end{array}$ & 10.3 & 11.7 & 10.2 & 9.8 & 9.4 \\
\hline $\begin{array}{c}\varepsilon_{1, \mathrm{u}, \mathrm{t}}, \\
\text { url } \times 10^{5}\end{array}$ & \multicolumn{7}{|c|}{ Dynamics $(\dot{\sigma}=70 \mathrm{MPa} / \mathrm{s})$} \\
\hline
\end{tabular}

Strains $\varepsilon_{1, u, t}$ little depend on the stress state type and level $\sigma_{2} / R_{b}$. So, at $\sigma_{2} / R_{b}=0.15$ a slight increase in the value of strain $\varepsilon_{1, u, t}$ is observed (by 10-13\% compared to the singleaxis tension), at further increase of $\sigma_{2}$ value the tendency to a slight decrease in strains $\varepsilon_{1, u, t}$ is observed (at $\sigma_{2} / R_{b}=0,6 \varepsilon_{1, u, t}$ less the similar strains calculated at single-axis tension by $10 \%)$.

Such state is true for both static and dynamic loading.

Full ultimate strains $\varepsilon_{1, \mathrm{u}}$ increase with the growth of $\sigma_{2} / R_{b}$. At that, increase of $\varepsilon_{1, \mathrm{u}}$ takes place, mainly, due to strains from the compressive load action at the first stage of loading, share of which in the full ultimate strain, while growth of $\sigma_{2} / R_{b}$, increases and at the level of $\sigma_{2} / R_{b}=0.6$ even exceeds the value of strains $\varepsilon_{1, u, t}$.

When analysing the loading rate effect on ultimate strains, it is noted that strains $\varepsilon_{1, \mathrm{u}, \mathrm{t}}$ and $\varepsilon_{1, \mathrm{u}}$ at dynamics turn out to be higher by $10-15 \%$, than similar strains at statics, both at single-axis tension and at "compression-tension" stress state with different level $\sigma_{2} / R_{b}$.

When analysing the results of P-2 series, first of all it is necessary to point out the following methodical difficulties that have appeared at the implementation of researches at "two compression-tension" stress state. As a result of the direct action on membrane device surface sensors their pressing in the concrete was observed, because of that it was impossible to record strains at the first stage of loading. In tension, it was necessary to record strains directly after the load increase at the stage. Further changes in the equipment readings, recording the growth of strains at the stage was connected with resistive strain gauges pressing in the concrete surface. These readings were excluded from the total deformation.

Besides, it is necessary to pointed out the fracture pattern of samples under dynamic loading. Fracture surface was formed at the top part of the sample in close proximity to the head. This is the zone of the single-axis tension, since due to design considerations the membrane unit is a few centimetres shorter than the sample. Thus, recorded values recorded of the strength loss can not be taken for the strength values at modelled SSS and hence to draw conclusions about the impact of the stress state type on the strength at the dynamic loading. 
Indicated effects did not appear at the static loading. From what it is possible to conclude that the increase in the loading rate increases the friction along the sample surface. Hereinafter it is needed to pay the special attention to procedures to reduce the friction.

Strength results are specified in Table 2.

Table 2. Results of strength determination at static and dynamic loading under conditions of singleaxis tension and "two compressions - tension" stress state (P-2 series).

\begin{tabular}{|c|c|c|c|}
\hline $\begin{array}{l}\text { Sample } \\
\text { No. }\end{array}$ & $\begin{array}{r}\text { Stress level } \\
\sigma_{2}\left(\sigma_{2} / R_{b}\right)\end{array}$ & $\begin{array}{l}\text { Strength } \mathbf{R}^{\sigma 2}{ }_{i b t} \\
\left(R^{\sigma 2}{ }^{2}, \mathrm{bt}, \mathrm{d}\right), \mathrm{MPa}\end{array}$ & $\begin{array}{l}\text { Strength average value } \\
R_{b t}^{\sigma 2}\left(R_{b t, d}^{\sigma 2}\right), \mathrm{MPa}\end{array}$ \\
\hline 1 & 2 & 3 & 4 \\
\hline \multicolumn{4}{|c|}{ Static tests } \\
\hline $\mathrm{O} 4$ & \multirow{2}{*}{0} & 1.4 & \multirow{2}{*}{1.45} \\
\hline O5 & & 1.5 & \\
\hline O9 & \multirow{3}{*}{0.3} & 1.9 & \multirow{3}{*}{1.78} \\
\hline $\mathrm{O} 12$ & & 1.8 & \\
\hline $\mathrm{O} 13$ & & 1.65 & \\
\hline \multicolumn{4}{|c|}{$\begin{array}{c}\text { Dynamic tests } \\
(\dot{\sigma}=70 \mathrm{MPa} / \mathrm{s}, \tau=0.05 \mathrm{~s})\end{array}$} \\
\hline O6 & \multirow{3}{*}{0} & 2.3 & \multirow{3}{*}{2.23} \\
\hline $\mathrm{O} 7$ & & 2.2 & \\
\hline O8 & & 2.2 & \\
\hline $\mathrm{O} 10$ & 0.3 & 2.2 & 2.2 \\
\hline
\end{tabular}

Double-sided drafting at $\sigma_{2}=\sigma_{3}=0.3 R_{b}$ increases the strength at the static loading by about $20 \%$. At that the dynamic strength is recorded at the strength level at the single-axis tension, however, taking into account described above fracture pattern, one should not be guided by these values as the final ones.

Diagrams of series P-2 concrete strain under static and dynamic loading at single-base tension and "two compression-tension" stress state are shown in Fig. 2.

Taking into account the limitations of obtained strain data, it is impossible to give a numerical estimate of longitudinal strain modulus values. Analysis of the available data does not allow speaking about an increase in the initial strain modulus with increasing loading rate, as it was in the case with $\mathrm{P}-1$ series samples.

At the dame time, it is possible to speak confidently about the reducing tension strain modulus with the growth of the stresses $\sigma_{2}=\sigma_{3}$ at both static and dynamic loading. Such modulus decrease is about $25 \%$. 


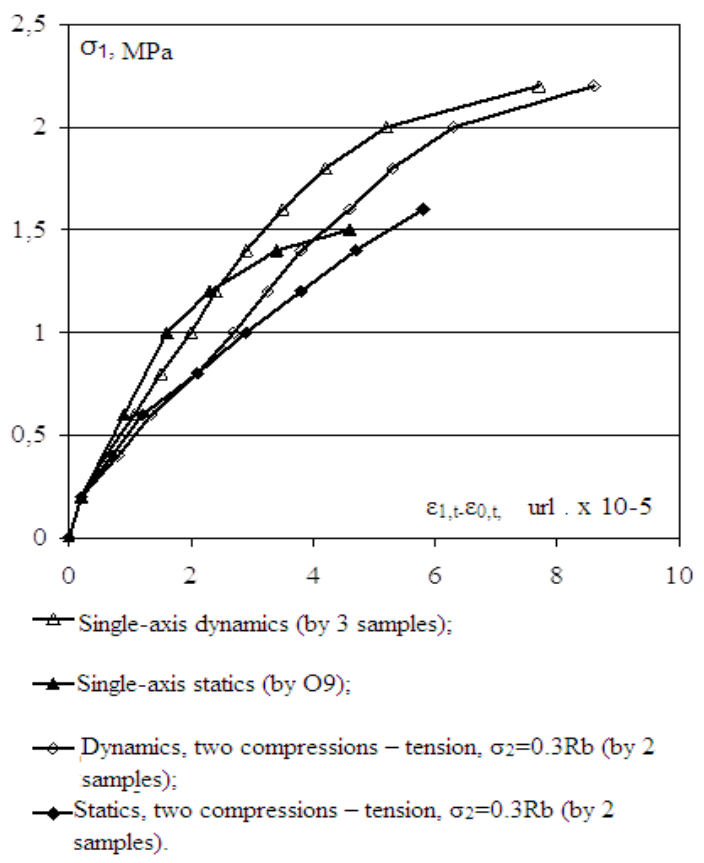

Fig. 2. Series P-2 concrete strain under static and dynamic loading at single-base tension and "two compression-tension" stress state.

Tendency of increasing ultimate longitudinal strains with the growth of the loading rate, which was observed in a testing of P-1 series samples, remained for P-2 series samples both at single-axis tension and at 'two compression-tension" SSS. When comparing longitudinal strain values at $0.9 \mathrm{R}$ level, it is possible to note that strains at dynamic impact exceed strains at statics by $35 \%$ at single-axis tension and by $10 \%$ at "two compression - tension" stress state at $3 \sigma_{2}=\sigma_{3}=0.3 R_{b}$.

\section{Conclusion}

1. Strength and strain characteristics (strain modulus and ultimate strains) of concrete at static and dynamic loading under conditions of single-axis tension and "tensioncompression"stress state were determined experimentally;

2. Regularities of the influence of stress state, stress level $\sigma_{2}$ and loading rate on the concrete strength were revealed. Criterion of the concrete strength at single-axis tension and "compression-tension" stress state was recorded, which takes into account these factors influence on the strength;

3. Initial modulus of strains and modulus, calculated taking into account the entire strain curve increases with increase of the loading rate (according to results of P-1 series tests);

4. Ultimate longitudinal strains increase with the growth of stress $\sigma_{2}$ for the value of strains from compressive load action at the first stage of loading. Maximum longitudinal strains from only tensile load action little depend on $\sigma_{2}$;

5. Ultimate longitudinal strains and maximum longitudinal strains from only tensile load action at dynamics by $10-15 \%$ exceed the similar strains at statics. 
6. In the course of testing at "compression-tension" 'stress state, methodical difficulties on modelling the specified SSS, connected with a significant increase of surface friction forces at the dynamic loading. In the future, it is necessary to solve the issues of improving the techniques of carrying out dynamic tests under conditions "two compression - tension" stress state.

The work is carried out pursuant to the grant of the Russian Academy of Architecture and Construction Science for young scientists

\section{References}

1. Y.N. Malashkin, I.M. Bezgodov, K.A. Tsvetkov, Natural and Technical Sciences.-, 1, 182-190 (2007).

2. N.F. Eremin, I.S. Tsurkov, Y.N. Malashkin, B.V. Tyablikov, I.M. Bezgodov, Study of concrete mechanical characteristics with account of its actual operation in hydraulic works, 62 (1978)

3. N.N. Popov, B.S. Rastorguev, A.V. Zabegaev, Calculation of structures for dynamic special loads, 319 (1992)

4. V.A. Kopnov, A.N. Voronin, Building mechanics of engineering structures and constructions. - 6, 7-11 (1996) 